\title{
Anaesthesia for organ transplantation
}

Adrian W. Gelb MBCH в FRCPC

\begin{abstract}
Advances in surgical, anaesthetic, and immunosuppressive techniques as well as increased public awareness have made organ transplantation a well accepted therapeutic modality. Transplantation has become the treatment of choice for selected patients with end-stage cardiac, liver, or kidney failure. The number of potential recipients has increased steadily. For example, at University Hospital the number of recipients has increased more than ten times over the past ten years. During the first eleven months of 1986, 90 kidncys, 43 hearts, 33 livers, and two heart-lungs were transplanted. Judging by the length of current waiting lists it is likely that other institutions will soon enjoy a similar experience.

Anaesthetists may become involved in the the transplantation process in one of three situations: (1) organ donor management, (2) anaesthesia for organ transplantation, and (3) anaesthesia of a transplant recipient hav ing unrelated surgery.
\end{abstract}

\section{Donor management}

Donor organs may be divided into the perfusable organs (kidney, liver, heart, lung, and pancreas) and the nonperfusable organs and tissues (eyes, skin, bone, heart valves, and dura mater). Anaesthetists will be involved in the management of perfusable organ donors as these patients need to have ventilation and organ blood flow maintained until the moment of harvesting. Anaesthetists have no direct role in the removal of non-perfusable tissues.

\section{Declaration of brain death}

The first step in donor management is the declaration of brain death. There are no statutory definitions of brain death in Canada. The Canadian Congress of Neurological Sciences has recently published new guidelines on the declaration of brain death. ${ }^{1}$ It is hoped that these will be nationally accepted and used. A declaration of brain death is usually based on clinical criteria. When the organs are to be donated for transplantation, at least two physicians not involved in the care of the recipient should certify that brain death has occurred. Special tests such as the electroencephalogram (EEG) or cerebral blood flow measurements are not usually required except in special circumstances.

\section{Organ donor maintenance}

After the declaration of brain death, the organ functions of a suitable donor must be maintained as carefully as prior to death (Table I). Without properly cared-for donors, transplantation of perfusable organs would not be possible. It may be useful to think of the organs as already belonging to the recipient and to accord to them all the therapeutic modalities, no matter how costly, that would be offered the recipient.

\section{SPECIFIC PROBLEMS}

Hypotension Hypovolaemia develops insidiously with brain death and accounts for most cases of haemodynamic instability. Causes include therapeutic dehydration in an effort to decrease ccrebral oedema, blood loss through haemorrhage, diabetes insipidus, osmotic diuresis due to hyperglycemia, and progressive reduction in systemic vascular resistance as a result of defective vasomotor control.

Aggressive fluid resuscitation should be monitored by intra-arterial and central venous (CVP) or pulmonary wedge pressure measurements. CVP or pulmonary wedge pressure should be kept in the $10-15 \mathrm{mmHg}$ range. Infusions of blood and blood products should be used when necessary. Vasopressors should only be used after adequate rehydration has been achieved. Dopamine is the agent of choice because it has the least detrimental effects on renal and splanchnic blood flow.

Arrhythmias. Atrial or ventricular arrhythmias may result from electrolyte imbalance, hypotension, vasopressors, and increased intracranial pressure. Therapy is as usual. Even with the most rigorous efforts, the inevitable deterioration of the brain-dead patient may lead to cardiac arrest. Cardiopulmonary resuscitation should be instituted in an attempt to re-establish cardiac rhythm and output. If the cardiac arrest oocurs in the operating room, it may be feasible to remove the kidneysand liver during CPR.

Deparment of Anaesthesia, University Hospital, University of Westem Ontario, P.O. Box 5339, Station "A," London, Ontario N6A 5A5. 
TABLE I Absolute and relative contraindications to organ donation

Age $>65$ years

Systemic sepsis

History of Hepatitis B

Acquired Immune Deficiency Syndrome (AIDS)

Intravenous drug user

Malignancy, except skin and CNS

Severe hypertension prior to brain injury

Prolonged high dose vasopressors

Prolonged hypotension

Prolonged anuria

Prolonged hypoxacmia

Donor organ disease or trauma

Transplant programs differ in the criteria used. Check with you regional transplant coardinator.

Diabetes insipidus. This is frequently seen in brain-dead donors and is usually accompanied by hypernatremia and hypovolaemia. If left untreated, urine output can rise to several litres per hour. Such polyuria may dilute the renal medullary concentrating gradient and reduce the responsiveness to subsequently administered Pitressin.

Urine output must be replaced hourly with intravenous crystalloid on a millilitre for millilitre basis. The electrolyte makeup of the fluid is dictated by the donor's serum electrolytes. If the urine output exceeds $300 \mathrm{ml} \cdot \mathrm{hr}^{-1}$, Pitressin should be used. A continuous intravenous infusion provides the greatest control and reduces the likeli. hood of complete renal shutdown. Start at a rate of 0.1 units $\cdot \mathrm{min}^{-1}$ and titrate as needed.

Oliguria. Low urine output (less $50 \mathrm{ml} \cdot \mathrm{hr}^{-1}$ ) is initially treated with rehydration. If this is not successful, lowdose dopamine $\left(2-3 \mu \mathrm{g} \cdot \mathrm{kg}^{-1} \cdot \min { }^{-1}\right)$ is used and failing that furosemide $1 \mathrm{mg} \cdot \mathrm{kg}^{-1}$.

Electrolytes. Serum electrolytes should be measured frequently so as to avoid hypernatremia and hypokalaemia especially in those patients with diabetes insipidus. If large volumes of dextrose containing solutions are used, then blood glucose should also be frequently measured.

Arterial blood gases. $\mathrm{PaO}_{2}$ should be kept between 70 and $100 \mathrm{mmHg}$. If the lungs are to be used for transplantation, then the lowest possible $\mathrm{FIO}_{2}$ without excessive positive end-expiratory pressure should be used.

$\mathrm{PaCO}_{2}$ and $\mathrm{pH}$ should be kept within the normal range by manipulation of the minute ventilation or the administration of sodium bicarbonate.

Hypothermia. Brain-dead patients are poikilothermic and may need very aggressive warming to maintain a temper- ature above $34^{\circ} \mathrm{C}$. Temperatures below this increase the likelihood of arrhythmias and make the declaration of brain death difficult.

\section{Intraoperative management}

Removal of the organs may be performed by a surgeon from one's own hospital or by an itinerant retrieval team. In the latter situation, the timing of the procedure may be dictated by flight schedules and weather conditions rather than the convenience of one's operating room.

The responsibilities of the anaesthetist are no different from those that usually pertain in the operating room the maintenance of tissue blood flow and oxygenation together with fluid, electrolyte, and acid base balance. Obviously, no drugs need to be given to ensure unconsciousness. The usual meticulous attention to circulatory and ventilatory homeostasis is required. The patient should be ventilated on at least the same $\mathrm{FiO}_{2}$ as used in the intensive care unit and vasopressors and Pitressin titrated as needed. Depending on the number of organs to be removed, the donor procedure may last from two to five hours.

It must be borne in mind and pointed out to ancillary operating room staff that the declaration of brain death does not require the loss of all reflexes, only the cerebral and brain stem reflexes. Retlex responses should therefore be expected. This can be most disconcerting and staff require frequent re-assurance that the donor is indeed brain-dead. The twitching of muscles or frank contraction may necessitate the use of non-depolarizing neuromuscular blocking drugs. Reflex haemodynamic nesponses to painful stimulation frequently occur. ${ }^{2}$ This may be due to reflexes involving the brain stem vasomotor areas which may still be intact, spinal reflexes, or adrenal medullary stimulation by a reflex arc. Therapy includes the weaning of vasopressors and on occasion the use of a vasodilator such as an inhalational anaesthetic or sodium nitroprusside.

\section{Heart transplantation}

After the first human heart transplant in 1967 , the initial enthusiasm for the procedure was followed by profound disappointment because of the high mortality. The development of new immunosuppressive agents, especially cyclosporine, has reduced the mortality so that one-year survival is now in excess of 80 per cent and five-year survival in excess of 50 per cent. ${ }^{3,4}$ This has once again stimulated interest in the procedure. At the beginning of 1986, there were approximately 120 centres world wide (75 per cent in North America) performing this procedure. By the end of 1986 there were another 170 North American institutions planning heart transplant programs. ${ }^{4}$ 
TABLE Il Potential adverse effects of immunosuppressive drugs

\begin{tabular}{|c|c|}
\hline Medications & Adverse effect \\
\hline $\begin{array}{l}\text { Antilymphocyte globulin } \\
\text { (ALG) }\end{array}$ & $\begin{array}{l}\text { Allergic reactions, hypotension, thrombo- } \\
\text { phlebitis, thrombocytopenia }\end{array}$ \\
\hline Azothioprine & $\begin{array}{l}\text { Leukopenia, thrombocytopenia, hepatic } \\
\text { dysfunction. Inhibits phosphodicsterasc } \\
\text { and may increase requirements for non- } \\
\text { depolarizing muscle relaxants }\end{array}$ \\
\hline Cyclosporine & $\begin{array}{l}\text { Nephrotoxic, hypertension (especially } \\
\text { heart transplants), hepatic dysfunction, } \\
\text { hyperkalaemia, hypomagnesaemia, } \\
\text { lymphoproliferative diseases }\end{array}$ \\
\hline $\begin{array}{l}\text { OK T3 monoclonal } \\
\text { antibody }\end{array}$ & $\begin{array}{l}\text { Fever, chills, tremor, chest pain, wheezing, } \\
\text { pulmonary oedema }\end{array}$ \\
\hline
\end{tabular}

Current waiting lists are relatively short (38 Canadians at the time of writing) but the National Heart Transplantation Study estimates that there are at least 14,000 North Americans who could be cansidered suitable for a transplant. It is therefore highly likely that many more anaesthetists will be involved with heart transplant patients either as part of the transplant team or caring for a transplant recipient having some unrelated surgery.

\section{Anaesthesia for heart transplantation}

The anaesthetic management is the same as that used for any patient with a severe cardiomyopathy and ventricular dysfunction. A pulmonary artery catheter is not usually placed preoperatively because of the increased risk of infection, arrhythmias, and the need to withdraw it when the recipient's heart is removed. A CVP is inserted using strict aseptic technique but not through the right internal or external jugular veins. The latter vessels are "saved" for the repeated endomyocardial biopsies that will be performed during follow-up. Weaning from cardiopulmonary bypass is usually unremarkable although small doses of inotropes or chronotropes may be needed.

\section{Anaesthesia in a patient with a transplanted heart}

A patient with a transplanted heart presents the anaesthetist with an unusual combination of problems which relate primarily to the use of immunosuppressive drugs and the altered cardiovascular responses to stress. Patients may present for the surgical correction of complications of their transplant e.g., abscess drainage or wound debridement, or for a totally unrelated surgical procedure. ${ }^{5}$ In the Pittsburgh experience, 28 per cent of their patients required a general surgical consultation and half of these patients required an operative procedure. ${ }^{6}$
Immunosuppressive drugs. The sequelae of long-term steroid administration are known to most anaesthetists. Complications of interest to anaesthetists from other immunosuppressive agents are shown on Table II. Anaesthetic drugs or techniques that reduce liver blood flow or that result in enzyme induction will have profound effects on cyclosporine blood levels.

Infection. Sepsis still remains the major cause of death in transplant recipients. All manipulations (IV access, intubation, plexus blockade) should be performed with an aseptic technique and as atraumatically as possible. Urinary catheterization should be avoided if possible.

Cardiovascular response. Many patients make a good functional recovery after heart transplantation although measured cardiac output is often lower than expected. The denervated heart does not respond to neurally mediated stimuli and does not give rise to ischaemic pain. The latter is an important consideration as accelerated atherosclerosis occurs in these patients. Although the heart does not respond to neurally mediated stimuli, the cardiac adrenergic receptors remain intact and respond normally to circulating catecholamines and receptor blockers. ${ }^{7}$ Pust-denervation hypersensitivity does not seem to be a clinical problem. Because of the denervation, no heart rate response is seen with atropine, neostigmine, digoxin, gallamine, and pancuronium. ${ }^{5}$

The response to stress follows a sequential pattem. ${ }^{8}$ Initially the left ventricular end diastolic volume increases which results in an increase in stroke volume by means of the Frank-Starling mechanism. This is not sustained but the increased cardiac output is maintained by an increase in heart rate which occurs over about five minutes. This is due to an increase in circulating catecholamines and the heart rate response tends to continue for a while after the period of stress. This relatively slow heart rate response makes tachycardia a poor indicator of depth of anaesthesia. Because the immediate response to stress is critically dependent on preload, these patients are profoundly sensitive to hypovolaemia.

Both atrial and ventricular arrhythmias are common in the recently transplanted patient but the incidence decreases with time. The rhythm disturbances usually respond normally to conventional antiarrhythmics but the negative inotropic effects of many of these drugs are exaggerated in the transplant patient. Cardioversion may therefore be safer.

\section{Liver transplantation}

The anaesthetic considerations for hepatic transplantation have recently been reviewed extensively. ${ }^{9-12}$ For 
the patient with a transplanted liver having unrelated surgery, the anaesthetic approach is identical to that used in any patient with liver disease. It appears that a normally functioning transplanted liver handles anaesthetic drugs nomally. However, there have been no formal or extensive studies of pharmacokinetics and pharmacodynamics in transplant patients.

\section{References}

1 Guidelines for the diagnosis of brain death. Can $J$ Neurol Sci 1986; 13: 355-8.

2 Wetzel RC, Setzer N, Stiff $J L$, Rogers $M C$. Hemodynamic responses in brain dead organ donor patients. Anesth Analg 1985; 64 : $125-8$.

3 Schroeder IS, Hunt SA. Cardiac transplantation: where are we? N Engl J Med 1986; 315: 961-3.

4 Crsscells $W$. Heart transplantation: recent policy developments. N Engl J Med 1986; 315: 1365-8.

5 Kanter SF, Samuels SI. Anesthesia for major operations on patients who have transplanted hearts, a review of 29 cases. Anesthesiology 1977; 46:65-8.

6 Steed DL, Brown B, Reilly JJ et al. General surgical complications in heart and heart-lung transplantation. Surgery 1985; $98: 739-45$

7 Cannom DS, Rider AK, Stinson EB, Harrison DC. Electrophysiologic studies in the denervated transplanted human heart. An J Cardiol 1975; 36: 859-66.

8 Pope SE, Stinson EB, Daughters GT, Schroeder JS, Ingels $N B J r$, Alderman $E L$. Exercise response of the denervated heart in long-term cardiac transplant recipients. Am J Cardiol 1980; 46: $213-8$.

9 Carmichael FJ, Lindop MJ, Farman JV. Anesthesia for hepatic transplantation: cardiovascular and metabolic alterations and their management. Anesth Analg 1985; 64: 108-16.

10 Borland LM, Roule M, Cook R. Anesthesia for pediatric orthotopic liver transplantation. Anesth Analg 1985; 64: 117-24,

11 Waterman PM. Anaesthesia for liver transplentation - a model for the anaesthetic management of end-stage hepatic failure. Can Anaesth Soc J 1983; 30: S34-S38.

12 Lindop MJ. Farman JV. Smilh MF. Anaesthesia: assessment and intraoperative management. In: Liver Transplantation. Calne RY (Ed.), Grune \& Stratton, Ncw York, 1983, pp. 121-43. 